\title{
X. Some unpublished data on Colour-Blindness
}

\section{Dr. William Pole F.R.S.}

To cite this article: Dr. William Pole F.R.S. (1892) X. Some unpublished data on Colour-Blindness, Philosophical Magazine Series 5, 34:206, 100-114, DOI: 10.1080/14786449208620169

To link to this article: http://dx.doi.org/10.1080/14786449208620169

曲 Published online: 08 May 2009.

Submit your article to this journal

Џll Article views: 2

Q View related articles $\sqsubset$ 
to be driven by rotation nearer to the longest diameter than is the material in the faces. Its maximum in the positive quadrant occurs at the point where

$$
\left.\begin{array}{rl}
p & =\sqrt{a b} \\
\text { i.e. } \tan \theta & =\sqrt{b^{3} / a^{3}}
\end{array}\right\}, . . . . . .
$$

where $\theta$ is the vectorial angle.

The corresponding maximum is given by

$$
\frac{a}{\mathrm{R}_{t}}=\frac{\omega^{2} \rho a^{2}}{\mathrm{E}} 2 \eta \frac{a-b}{a} \frac{a^{4}-2 \eta a^{2} b^{2}+b^{4}}{3 a^{4}+2 a^{2} b^{2}+3 b^{4}} .
$$

This vanishes of course in a circular disk for all values of $\eta$ and for $\eta=0$ in all forms of disks.

$\S 34$. In a circular disk every line originally parallel to the axis of rotation has a plane containing that axis for osculating plane. Calling the radius of curvature in a line at distance $r$ from the axis of rotation $\mathrm{R}_{r}$, we easily find from $(67)$

$$
\left.\begin{array}{l}
a / \mathbf{R}_{r}=\left(\omega^{2} \rho a^{2} / \mathrm{E}\right) \times(r / a) \times \eta(1+\eta) \\
a / \mathbf{R}_{a}=\left(\omega^{2} \rho a^{2} / \mathrm{E}\right) \times \eta(1+\eta)
\end{array}\right\}
$$

Comparing (73) with (38) and (37), we find between the curvature in a generator of the rim and that at the centre of a face of a circular disk the simple relation

$$
l / \mathbf{R}_{a}=a / \overline{\mathbf{R}} \text {. . . . . . . . }
$$

Thus in a thin disk the curvature produced by rotation in a rim generator is much greater than that produced at the centre of the faces. The curvature in the rim generator might perhaps be measured by an optical method, at least in a circular disk.

\section{Some unpublished Data on Colour-Blindness. By Dr. Wrlutam Pole, F.R.S.*}

[Plate II.]

THESE data have reference to a paper "On ColourBlindness" which the Royal Society did me the honour to publish in the Philosophical Transactions of 1859 , and a Report on which, by Sir John Herschel, was printed in the 'Proceedings,' vol. x. p. 72. There were some points in this

* Communicated by the Author. 
paper left incomplete, and I was advised to add supplementary explanations, but, for various reasons, this was not done. As, however, there is still much uncertainty and misunderstanding on the subject generally, it appears to me that, even after this lapse of time, it may be useful to put on record any facts or observations which may tend to throw light upon it.

The paper contained, so far as I know, the earliest complete quantitative demonstration of the general facts of dichromic vision, made, at the suggestion of Prof. Stokes, by Clerk Maxwell's elegant device of the colour-top, then newly introduced. I carried out the necessary series of experiments, first on my own vision, and afterwards on that of some other persons reputed to be colour-blind; and I was surprised to find in the latter an anomaly which led me to add the following postscript, dated October 1859 :-

"Since the foregoing paper was written $I$ have had the opportunity of examining three colour-blind persons, and have found that the vision of each is perfectly dichromic, corresponding precisely in general character with my own. But the remarkable feature has presented itself, that the coefficients of the colour-top equations vary considerably in the different cases. Thus, for example, although my equation XV. will always hold in its general form,

$$
m \text { Vermilion }+n \text { Ult. }=p \text { Black }+q \text { White, }
$$

yet the values of $m, n, p$, and $q$ will vary for different individuals."

The observations themselves were not given, but I propose to add them now, with others, as being in many respects of permanent interest.

Two of the persons examined were brothers, named NicollCarne, gentlemen of high position and education, residing near Cowbridge in South Wales; and they had already, at a much earlier time, acquired some public celebrity in regard to this matter. On the 25th of June, 1816, a paper was read before the Royal Medical and Chirurgical Society of London by Whitlock Nicholl, Esq., M.D., of Cowbridge, entitled "Account of a curious Imperfection of Vision;" and it referred to " a boy 11 years old, clever, lively, and healthy," who made the kind of mistakes which are now so familiar to us, but which were then thought so strange and unaccountable. He was said also to have "an infant brother," of whose vision nothing could then be known. Now these two brothers were the gentlemen whom, forty-three years afterwards, I accidentally heard of, and who kindly gave me permission to examine their vision. I may give the following extracts from leiters received from one of them :- 
"Nash Manor, June 1859."

"The great peculiarity of my case is that it has existed in my family, as far as we have been able to trace, for generations, and has always skipped over the female brauches, although, as in my own case, it has been transmitted through them.

"My brother has the same peculiarity of vision.

"I have long been convinced that I really see but three colours, viz. blue, yellow, and white, and the absence of all colour, black. By taking the water-colours gamboge, Prussian blue, and Indian ink, I can produce all the colours I see in Nature. I form $m y$ reds, greens, and browns by combinations of yellow and black; pinks and crimsons by light and dark blue. The rainbow appears to $m e$ to be composed of but two well-defined and distinct bands. stripes, or colours, the one shaded from light to dark blue, and the other shaded from light to dark yellow."

\section{"R. O. Nicoll-Carne."}

I visited these gentlemen on the 14th of July, 1859. They had nover before been subjected to any precise or quantitative experiments, and I am glad to have the opportunity of recording the actual facts of their vision. Both brothers took part in the examination, and their colour-impressions, so far as I could tell, appeared precisely similar.

I also examined a Mr. Lloyd, a middle-aged gentleman of good intelligenee, but not pretending to scientific knowledge ; and a fourth example was Mr. Parry, a professional chemist, whose case was peculiarly useful as forming the greatest contrast with mine.

In all these cases I followed the same plan. After a preliminary examination with the Chevreul circle and "gammes," I obtained their matches with the revolving-disk tests, in the manner described for hyself in par. 19 of my paper. I have collected the whole of the equations at the end of this article, and I have added the case of Mr. Simpson, who was tested by Prof. Clerk Maxwell about the same time, with, I believe, the same colours.

I am also able to add to these, by indirect evidence, another case of great celebrity, namely that of John Dalton. Sir John Herschel was good enough to submit for my examination the data he had obtained from Dalton, as mentioned in the well-known letter of 1833 ; and I had no difficulty in establishing the general similarity between Dalton's vision and my own, subject to certain variations of the kind I am now considering *. And, further, I found some data by which to estimate roughly the nature and extent of these variations. He had pointed out samples of red and green silk, which

* See 'Contemporary Review,' May 1880, for further' particulars. 
seemed a very near match to him; while to me there was the difference that the green was the darker by two numbers of Chevreul's yellow gamme. This fixed Dalton's variation as about intermediate between my two extremes, probably corresponding pretty nearly with Mr. Lloyd's.

The quantitative data here collected, and all comparable, furnish very important materials for inference and reasoning as to the still open question of the varieties of colour-blindness. It is not my object to enter further on that argument now, but it is necessary to show that, in order to make use of the facts by proper classification, more detailed attention must be devoted to the minute peculiarities of dichromic vision; and this opens another point in which my original paper was deficient. I had given a general comparison between the normal and the dichromic hues seen, referring briefly to various tints and shades of them; but it is now necessary to examine these tints and shades more accurately than has, I think, hitherto been done. For the proper understanding of what we really do see depends almost entirely on this point, and it is often much misunderstood.

Although the dichromic patient, as his name implies, sees only two varieties of hue, yet the number of colour-impressions he derives from these admit of great diversity of character ; and this is the reason why his defect so often escapes notice. He hears of the variety in colour presented by nature ; and he knows that nature also offers great variety to him : what he does not know till he is taught, is the different nature of the variety in the two cases. It is this we have now to explain.

The colour-impressions received in dichromic vision may be classed in eleven species, seven of which further admit each of infinite variety in degree. And in describing them I shall adhere, without discussion, to my original names of yellow and blue for the two hues seen. Then we have:-

1. The impression of the full yellow colour in its most powerful form.

2. The corresponding impression of the full blue colour.

3. Then there is the impression of what Sir John Herschel called "the equilibrium of the two," or full white. And

4. There is what he called the "negation" of the two, $i$. e. black.

According to the method of testing by pigments, these four form what we may call the fundamental colour-impressions of dichromic vision, by combinations of which all other colourimpressions are produced. These combinations form by far the most important part of the visual phenomena, and require 
therefore special study. They belong, as already stated, to seven species.

5. An infinite variety of impressions may be given by diluting the fundamental yellow with different proportions of white. The painters have a practical name for these, namely tints ; but we want, for quantitative purposes, another form of expression. The freedom of a colour from white is usually called, in this country, "purity;" but it will suit our present object better to adopt the equivalent of the German term Sättigung. Helmholtz, for example, repeatedly uses such expressions as "höchste Sättigung," or "bei sehr gesättigten Farben ;" and I propose to define these mixtures as degrees of saturation. If to $y$ parts of yellow we add $w$ parts of white, then the resulting "degree of saturation" is $=\frac{y}{y+w}$, the full saturation of the yellow colour being $=1$.

6 . Then we have an infinite variety of impressions of a different kind, by darkening the fundamental yellow with black. These modifications painters call shades, and we may term them degrees of brightness or degrees of luminosity. Thus, if to $y$ parts of yellow we add $b$ parts of black, the degree of luminosity will be expressed by $\frac{y}{y+b}$, the original luminosity of the yellow colour being $=1$.

7. But there is another infinite variety of impressions obtainable by mixing yellow with different proportions of both white and black, by which its saturation and luminosity are both reduced, and the character of the impression is materially changed. If $y$ parts of yellow are mixed with $v$ parts of white, and $b$ parts of black, the degree of saturation will be $=\frac{y+b}{y+b+w} ;$ and the degree of luminosity $=\frac{y+w}{y+w+b}$.

$8,9,10$ are corresponding varieties of impression for the blue colour.

11. Then, finally, there is an infinite variety of impressions of "grey," formed by mixing white and black in different proportions. The luminosity of any such mixture will be $=\frac{w}{w+b}$.

The mixtures of yellow with blue produce no new impressions-none but what are included in the above classes.

It is worth while also to define another quantitative function of the dichromic mixtures, $i$. e. the strength or power of the impression of the colour proper, in relation to the full power of the hue from which it is derived. I propose to call this the 
chromic strength. In class 5 this will be the same thing as the degree of saturation ; in class 6 it will be the same as the degree of luminosity; but in class 7 it will be $=\frac{y}{y+w+b}$.

Now, having defined quantitatively the different varieties of dichromic colour-impressions, we ought to be able to represent them in graphic form ; and this is another point in which my original paper required supplementing. Professer Clerk Maxwell, who was kind enough to take much interest in my case, pointed this out to me, referring me to the explanation he had given on the subject in the Phil. Trans. for 1860 . The system he there laid down, founded on Newton's law for colour mixtures, has-since become well known to earnest students. For normal vision an equilateral triangle is drawn, and on its three angles are supposed to be located the three fundamental colour-sensations-red, green, and violet, by combinations of which, according to Young's theory, all hues are formed. Then every possible hue will be represented by a point within the triangle, which can be determined by Newton's rule.

The application of this, however, to dichromic vision has never yet received proper attention. Maxwell, in his fig. 11, gave an example, the object of which was to compare dichromic with trichromic vision, and for which, therefore, he used the normal triangle. But, to show simply the phenomena of dichromic cases, or to compare them with each other, this becomes unnecessarily complicated, and makes a clumsy figure. We know nothing of red, green, or violet (none of them existing in our system), and have no inducement to base our triangle upon them; and, moreover, we have none of the varieties of hue, to depict which the normal triangle is formed.

For these reasons, availing myself of a suggestion made to mo by Lord Rayleigh, I have adopted a different arrangement of the diagram, which, while founded on the same principles, shall be specially adapted to the facts of our vision. I retain the equilateral triangle, but I place on its three angles the three chief sensations received by dichromic eyes; i.e. the warm colour, the cold colour, and the sensation of their "equilibrium," white. I then find an additional point for their "negation," black, and thus I get the four starting-points of the colourimpressions which it is the object of the diagram to portray.

The construction will be readily understood from fig. 1, where $\mathrm{Y}$ is the warm colour, yellow ; $\mathrm{U}$ is the cold colour, ultramarine blue; and $\mathrm{W}$ is white ; the point for black is determined for each special patient by equation I. For my vision 
the line YU must be divided at $O$ in the proportion of $61 \frac{1}{2}$ to $38 \frac{1}{2}$, and a line must be drawn from $W$ through 0 and prolonged downwards. The distance WO being taken as 64 parts, the prolongation must be made 36 parts, which will give the point Bk. Then the lines from this point to $\mathrm{Y}$ and U will complete the figure. It will now be easy to see how all the varieties of our colour-impressions, above described, may be represented on the diagram.

The simple impressions $1,2,3,4$ are on the angular points. The line YW contains the whole series of class 5 ; the line UW the whole series of class 8 ; the line Y Bk contains the whole series of class 6 ; the line $U$ Bk, that of class 9 ; the line W Bk contains the whole series of greys in class 11 . The position of a point representing any given mixture along these lines is fixed by the usual Newton's rules; thus a mixture of half yellow and half white would lie halfway between $\mathbf{Y}$ and $W$. A mixtare of one part yellow and 3 parts black would lie at a distance from $\mathrm{Bk}$ of one fourth the length of the line.

The impressions in classes 7 and 10 are represented by points lying in the interior of the figure; No. 7 (yellow) lying all on the left-hand side of the grey line; No. 10 (blue) all on the right-hand side. The mode of finding the position of any point will be best shown by an example: take the emerald green as defined by my equation IX. First divide the grey line into $(58+19=) 77$ parts, of which set off 19 at the lower end, giving a point $a$. From this draw a line $a \mathbf{Y}$, divide it into 100 parts and set off 23 of these from $a$. This will give the point $G$, representing my emerald green. The various quantities relating to this impression may be determined geometrically as follows :-Draw a line from $W$ through the colour-point $\mathrm{G}$, cutting the line $\mathrm{YBk}$ in $s$; then the degree of saturation $=1-\frac{\overline{s \mathrm{G}}}{s \overline{\mathrm{W}}}$. Similarly draw a line from $\mathrm{Bk}$ throngh $\mathrm{G}$, cutting $\mathrm{WY}$ in $l$, then the degree of luminosity $=1-\frac{\overline{l \mathrm{G}}}{\overline{\overline{\mathrm{B}}}}$, and the elromic strength $=\frac{\overline{a \mathrm{G}}}{\overline{a \mathrm{Y}}}$.

If a line be drawn from vermilion, or from any red colour, to $\mathrm{U}$, the point where it crosses the line $\mathrm{W} \mathrm{Bk}$ will represent a colour which, though a powerful crimson or "purple" to the normal eye, will be grey to dichromic eyes, or, in other words, a red invisible to them. And, similarly, in a line GU, the point where it cuts the grey will be an "invisible green."

In this way, the figure, when completed for the various 
colours used in the tests, will give, at a glance, a perfect idea of the phenomena of vision of the dichromic patient; and by the simple application of a pair of compasses, the quantitative determinations may at once be found.

It will now be easily seen that the difference between this diagram and Maxwell's normal one exactly expresses the essential difference between normal and dichromic vision. In the former the most salient feature is the immense variety of hues; the normal-eyed person has not only six chief colours, each one differing essentially from all the rest, but their combinations with each other afford an infinity of additional varieties of hue. This variety is wanting in dichromasie, but its place is supplied by an infinity of varieties of tint and shade.

Now in both diagrams the area of the figure may be filled with innumerable points, each of which will express a different variety of colour-impression; but while in the normal case these are varieties of hue, in the dichromic case they are varieties of tone.

The want of appreciation of this difference becomes continually evident in communications between normal and colour-blind people; the two parties being frequently quite at a loss to understand each other; and it accounts for some of the mistaken views held by normal-eyed persons, even those who have studied colour, as to what our impressions really are. The errors often made by them in describing our sensations seem quite as ludicrous to me, as any attempts of mine to identify the normal colours would be to them.

The same consideration influences the discussions on the the alleged danger with railway signals. The alarmists think it quite sufficient to say that " the colour-blind are unable to distinguish between red and green." But this is speaking in an unknown tongue. The point to test is, "whether the peculiar variety of colour-impression made on the dichromic eye by the red-lamp rays is so different from that made by the green-lamp rays, that the distinction between them is easily perceived." This is a form of the problem not often thought of.

Fig. 1 is the diagram of my own vision. Fig. 2 is that of Mr. Parry, which forms the greatest contrast to mine. It is not necessary to give the intermediate ones; but the important results are recorded in the following table, which will be a useful addition to the simple elementary data. 
TABLE of the Comparative Colour-Impressions produced by the rays of various coloured pigments upon several individuals, each having Yellow and Blue Dichromic Vision.

The full Saturation, Luminosity, and Chromic Strength of the fundamental colour-disk used are each denoted by unity.

\begin{tabular}{|c|c|c|c|c|c|}
\hline & Pole. & Simpson. & $\begin{array}{c}\text { Lloyd } \\
\text { and } \\
\text { probably } \\
\text { Dalton. }\end{array}$ & $\begin{array}{c}\text { Two } \\
\text { brothers } \\
\text { Carne. }\end{array}$ & Parry. \\
\hline 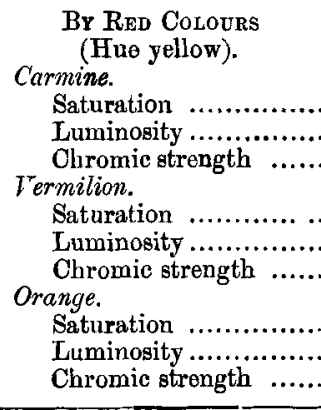 & $\begin{array}{c}1 \cdot 01 * \\
\cdot 10 \\
\cdot 10 \\
1 \cdot 00 \\
.235 \\
\cdot 235 \\
1 \cdot 00 \\
\cdot 50 \\
\cdot 50\end{array}$ & $\begin{array}{r}\cdots \\
\cdots \\
\cdots \\
0 \cdot 95 \\
18 \\
\cdot 13 \\
\cdots \\
\cdots \\
\cdots\end{array}$ & $\begin{array}{c}1 \cdot 00 \\
.04 \\
.04 \\
\\
0 \cdot 95 \\
\cdot 135 \\
.085 \\
\\
\cdots \\
\cdots \\
\cdots \\
\end{array}$ & $\begin{array}{r}\cdots \\
\cdots \\
\cdots \\
1 \cdot 00 \\
\cdot 08 \\
\cdot 08 \\
\cdots \\
\cdots \\
\cdots \\
\end{array}$ & $\begin{array}{r}1.00 \\
.03 \\
.03 \\
1.00 \\
.08 \\
.08 \\
1.00 \\
.35 \\
.35\end{array}$ \\
\hline 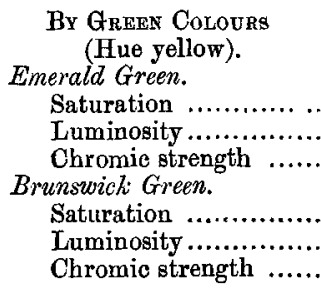 & $\begin{array}{c}0.81 \\
.42 \\
.23 \\
0.97 \\
.125 \\
.095\end{array}$ & $\begin{array}{l}0.78 \\
0.55 \\
0.33 \\
\\
\ldots \\
\ldots\end{array}$ & $\begin{array}{r}0 \cdot 74 \\
\cdot 54 \\
\cdot 28 \\
\\
1 \cdot 00 \\
\cdot 12 \\
\cdot 12\end{array}$ & $\begin{array}{r}0.81 \\
\cdot 61 \\
\cdot 42 \\
\\
\ldots \\
\cdots \\
\cdots\end{array}$ & $\begin{array}{r}0.87 \\
.56 \\
\cdot 43 \\
0.98 \\
\cdot 17 \\
\cdot 15\end{array}$ \\
\hline $\left.\begin{array}{c}\text { BY Vermilion and BLUE. } \\
\text { Proportion of blue for } \\
\text { neutralization ......... } \\
\text { Proportionateluninosity } \\
\text { of the resulting grey... }\end{array}\right\}$ & $\begin{array}{l}0.37 \\
0.16\end{array}$ & $\begin{array}{l}0 \cdot 18 \\
0 \cdot 12\end{array}$ & $\begin{array}{c}0.12 \\
0.11\end{array}$ & $\begin{array}{l}0 \cdot 11 \\
0.04\end{array}$ & $\begin{array}{l}0 \cdot 11 \\
0 \cdot 08\end{array}$ \\
\hline $\begin{array}{l}\text { By EMerald Greme aNd } \\
\text { BLUE. } \\
\left.\begin{array}{c}\text { Proportion of blue for i } \\
\text { neutralization .......... } \\
\text { Proportionateluminosity } \\
\text { of the resulting grey }\end{array}\right\}\end{array}$ & $0 \cdot 30$ & $\begin{array}{l}0.47 \\
0.40\end{array}$ & $\begin{array}{l}0.43 \\
0.35\end{array}$ & $\begin{array}{l}0 \cdot 61 \\
0 \cdot 35\end{array}$ & $\begin{array}{l}0.66 \\
0.33\end{array}$ \\
\hline $\left.\begin{array}{c}\text { BY YelLow aNd BluE. } \\
\text { Proportion of blue for } \\
\text { neutralization ......... } \\
\text { Proportionateluminosity } \\
\text { of the resulting grey ... }\end{array}\right\}$ & $\begin{array}{l}1 \cdot 6 \\
0 \cdot 36\end{array}$ & $\begin{array}{l}1 \cdot 4 \\
0 \cdot 31\end{array}$ & $\begin{array}{l}1.5 \\
0.35\end{array}$ & $\begin{array}{l}1 \cdot 44 \\
0 \cdot 31\end{array}$ & $\begin{array}{l}1.5 \\
0 \cdot 40\end{array}$ \\
\hline
\end{tabular}


Then, finally, there was another incompleteness in my paper, pointed out by Sir John Herschel. He was pleased to say, in a letter to me dated 14th November, 1856 , that he " thought my paper had exhausted the part of the subject referring to absorptive or negative colour (that with which painters and dyers were conversant)," but he recommended that I should follow up the communication with another, giving more attention to the prismatic phenomena, which he termed positive colour. Soon after this, Professor Clerk Maxwell undertook to make with me the necessary experiments on the prismatic colours, by the aid of the colour-box described in his paper of 1860 . They made some progress, but were unfortunately never completed. Since that time several observations on dichromic vision with spectral colours have been published. They agree in general character, but fully confirm the tendency to variability in the quantitative details. It will suffice here to give a general description of the appearance of the spectrum, according to my vision, with the view of showing its analogy to my colour-impressions from pigments, as above described.

The two diagrams, figs. 3 and 4 , will illustrate the comparison between the normal and the dichromic views of the spectrum. Fig. 3 gives the ordinary Newtonian colour divisions. Fig. 4 describes the appearance of the corresponding parts to my eyes.

My whole spectrum is coloured, mostly very vividly. It is divided into two lengths ; the left-hand division being oceupied by various modifications of my less refrangible colour, yellow; the right-hand by precisely similar and symmetricallyarranged modifications of my more refrangible colour, blue.

Much interest attaches to the point of division between the two colours. It must not be supposed that there is any distinct line*, it is simply the place (by no means well defined, for physiological reasons often explained) where the two colours, becoming gradually fainter or paler as they approach on either side, at last lose their hue and merge together. This place is called the neutral point. Its position varies a little with different persons, and even for the same person with different lights; but it is generally somewhere near midway between the Fraunhofer lines $b$ and $F$; and for me its wave-length is about 500. In the normal spectrum this point is, I believe, a powerful blue-green.

* It is sometimes asserted that there is a colourless band here of greater or less width. I can only say I never saw such a band myself, nor can I understand how such a band could be formed, according to the known origin of the eppearances. 
I may now describe the appearance of the colours on each side, beginning with the left-hand or yellow division. Proceeding from the neutral point towards $b$, the sensation of the yellow colour immediately comes in, but at first very faint and pale, being much diluted with white; but as we go further the saturation gradually increases until, beyond the colour becomes a beautiful resplendent fully-saturated yellow.

This continues for some distance, until, somewhat beyond D, the strength of the colour begins to fall off again. But the change now is of a nature different from that already described in coming from the neutral point. There is here no dilution with white, the saturation remains full and constant, the change being a diminution of luminosity only. This diminution increases gradually, giving an appearance like that of the shading of a round column in an engraving, and it increases in darkness till the visible spectrum ends. But the saturation of the colour is fully maintained the whole way, and some good authorities contend that it even increases towards the end*. This fact is very important, for the high saturation of the dark yellow at the end of the spectrum gives so novel an effect as often to lead dichromic patients to believe they really see a third colour there, and so to give an erroneous account of their vision. This error was fallen into by no less a person than John Dalton, and it was the cause of the long delay in the general acceptance of Herschel's dichromic explanation.

The length of the spectrum visible is, I believe, variable even with normal-eyed persons; with dichromic vision it is often considerably shortened at the red end. But that is not my case ; Sir John Herschel, who had expected a shortening, soon found I had none, and repeated comparisons have confirmed his statement.

The arrangement of the colouring in the more refrangible division of the spectrum is precisely similar to that already described. Starting from the neutral point, the blue colour enters, at first much diluted with white, but gradually strengthening till it becomes brilliant and fully saturated between $F$ and $G$. Beyond this it is gradually darkened, but still preserving its saturation till it disappears.

The actual vividness, to me, of my two colours, in their maximum saturation and luminosity, $i$. $e$. near $D$ and between $F$ and $G$, has been found to be nearly the same as for normal eyes.

* See some slight indication of this by the increased figure for the saturation of carmine on page 108. 
In order, now, to show the connexion between these appearances and those of the pigmental colours, it is necessary to state how the spectrum appearances are explained. For this purpose I have added the diagram, fig. 5, of the two colour sensations in the manner shown by Clerk Maxwell in his paper of 1860 . The ordinates of the curves ${ }^{*}$ give a general idea of the variations of the luminous strength of the sensations at the various points of the wave-length. Beginning at the left-hand end of the figure, the yellow curve near its origin has a small ordinate, and consequently the colourimpression is dark. But further on the luminosity rapidly increases till it arrives at its maximum. This series of colourimpressions, therefore, exantly corresponds to the pigmental class No. 6, i.e. yellow fully saturated, but darkened by varying gradations of illumination.

A little beyond the maximum, where the yellow curve begins to descend, a new element comes in, as we enter on the wave-lengths which excite the other or blue curve; and beyond this we have both the yellow and blue acting together. The effect of this mixture is to make white, and so to dilute the yellow colour, and to diminish its saturation. This accounts for the paler hue of the yellow as it approaches the neutral, the dilution constantly increasing till the power of the two colours becomes equilibrated, when the yellow disappears and we get the neutral hue.

In this part of the spectrum, therefore, we have two causes of diminution of chromic strength : first the gradual loss of luminusity of the yellow (indicated by the reducing ordinate), and, secondly, the gradual loss of its saturation. This combination will at once identify the colour-impression with the pigmental class 7 , where the yellow is mixed with both white and black.

The blue division of the spectrum is subject to a precisely similar explanation.

The position of the neutral point, in the powerful bluegreen, shows that the particular normal green hue at that place is invisible as a separate colour to the dichromic eye. But it has been explained in my paper that there is also a hue of red, which is invisible. This does not exist in the spectrum, but by mixing a spectral red with a spectral blue or violet in proper proportions, the invisible hue is obtained. Helmholtz calls it purple, and it is, to the normal eye, the complement of the invisible green.

* These curves do not express any definite magnitudes or quantitative data. Prof. Maxwell did, I know, get out the exact curves for my vision, and promised them to me, but I never had them. They will, however, I think, not differ much from those here shown. 
It is easy from these explanations to give the gener'al location of the spectral colours on the diagram fig. 1. From the first visibility at the red end the colour-impressions, beginning at $\mathrm{Bk}$, will lie along the line $\mathrm{BkY}$, till they reach the maximum brilliancy at $\mathrm{Y}$, corresponding to the normal yellow part of the spectrum. From that they will pass along or near the line $\mathrm{YU}$, till at 0 , corresponding to w.-1. 500, they reach the neutral point where the yellow hue ends. Then, continuing along the same line, the blue sensation will come in, and will increase to its maximum (between $\mathrm{F}$ and $G$ ) at $U$, after which it will return by the line UBk till the visible spectrum ends. In other words, the line of the spectral colour-impressions is simply along the lines of the lower triangle, $\mathrm{Bk}, \mathrm{Y}, \mathrm{O}, \mathrm{U}, \mathrm{Bk}$. The exact gradations and positions along this course will vary with different individuals, and can, by proper observations, be easily plotted for any individual in their true geometrical position.

I believe this gives what Sir John Herschel recommended me to do, and so completes, according to his expression, the "exhaustive" description of the phenomena of the yellow and blue dichromic vision, characterizing the great mass of the persons said to be "colour-blind." I have, I am afraid, gone into what may seem, to outsiders, a large amount of detail as to the facts of the case ; but, in the present unsatisfactory state of knowledge of the subject, I believe it is only by a more careful study of the actual facts that there can be any hope of a better state of things.

Athenæum Club, S.W.

William Pole.

May, 1892.

APPENDIX.

TABLE of Comparative Colour-Equations of different persons, to illustrate the varieties existing in Yellow and Blue Dichromic Vision.

These equations were taken by Prof. Clerk Maxwell's Colour-top, using the following colour cards supplied under his direction (1858-9) :-

Yellow (Pale or Lemon Chrome) Orange Chrome, Vermilion, Carmine, Ultramarine, Blue Verditer, Emerald Green, Brunswick Green, Black, White.

Mr. PoLE.

I. $38 \frac{1}{2}$ Y. $+61 \frac{1}{2}$ Ult. $=64$ Black $+36 \mathrm{Wh}$.

II. 62 Y. +38 Ult. $=78$ Orange chro $+22 \mathrm{Wh}$.

III. 51 Y. +49 Ult. $=88$ Emerald gr. $+12 \mathrm{Wh}$. 
IV. $48 \frac{1}{2} \mathrm{Y} .+51 \frac{1}{2}$ Ult. $=70$ Vermilion $+30 \mathrm{Wh}$. V. $42 \frac{1}{2}$ Y. $+57 \frac{1}{2}$ Ult. $=66$ Carmine +34 Wh. VI. $42 \frac{1}{2}$ Y. $+57 \frac{1}{2}$ Ult. $=68 \frac{1}{2}$ Brunsw. gr. $+31 \frac{1}{2}$ Wh.

VII. 20 Y. $+80^{2}$ Ult. $=65$ Blue verditer +35 Black. VIII. 50 Y. +50 Blk. $=100$ Orangechrome. IX. 23 Y. +58 Blk. +19 Wh. $=100$ Emerald green. X: $23 \frac{1}{2}$ Y. $+76 \frac{1}{2}$ Blk. $\quad=100$ Vermilion. XI. 10 Y. +90 Blk. $=99$ Carm +1 Wh. XII. $9 \frac{1}{2}$ Y. $+87 \frac{1}{2}$ Blk. $+3 \mathrm{Wh} .=100$ Brunsw. green. XIII. 70 Ult. +30 White $=100$ Blue verditer. XIV. 73 Emerald gr. +27 Ult. $=70 \frac{1}{2}$ Blk. $+29 \frac{1}{2}$ Wh. XV. 73 Vermilion +27 Ult. $=83 \frac{1}{2}$ Blk. $+16 \frac{1}{2} \mathrm{Wh}$. XVl. 86 Carmine +14 Ult. $=93$ Blk. $+7^{2}$ Wh. XVII. 87 Brunswick gr. +13 Ult. $=90$ Blk. +10 Wh. XVIII. 68 Blue verditer $+32 \mathrm{Y} .=51$ Blk. +49 Wh. XIX. 84 Verm. +16 White $=85$ Emer. gr. +15 Blk. XX. 75 Carm. +10 Y. +15 W. $=76$ Emer. gr. +24 Blk. XXI. 96 Carm. +4 White $=100$ Brunsw. gr. (nearly).

\section{Mr. Simpson.}

(Experiments by Prof. Clerk Maxwell.)

I. 42 Y. +58 Ult. $=69$ Blk. +31 Wh.

III. 56 Y. +32 Ult. +12 Wh. $=100$ Em. gr.

IV. 47 Y. +53 Ult. $=70$ Verm. $+30 \mathrm{Wh}$.

IX. 33 Y. +45 Blk. +22 Wh. $=100$ Em. gr.

X. 13 Y. +82 Blk. +5 Wh. $=100$ Verm.

XIV. $68 \mathrm{Em}$. gr. +32 Vlt. $=60$ Blk. $+40 \mathrm{Wh}$.

XV. 85 Verm. + 15 Ult. $=88$ Blk. $+12 \mathrm{Wh}$.

XIX. 96 Verm. +4 Wh. $=31$ Em.gr. +69 Blk.

\section{Mr. LLOYD.}

(With which John Dalton's vision may probably approximately agree.)

I. 40 Y. +60 Ult. $\quad=65$ Blk. $+35 \mathrm{Wh}$.

III. 57 Y. +43 Ult. $\quad=100$ Em. gr.

IV. 44 Y. +56 Ult. $=71$ Verm. $+29 \mathrm{Wh}$.

IX. 28 Y. +46 Blk. +26 Wh. $=100$ Em. gr.

X. $8 \frac{1}{2}$ Y. $+86 \frac{1}{2}$ Blk. +5 Wh. $=100$ Verm.

XI. $4 \frac{1}{4}$ Y. $+95 \frac{3}{4}$ Blk. $\quad=100$ Carmine.

XII. 12 Y. +88 Blk.

$=100 \mathrm{Br}$. gr.

XIV. 70 Em. gr. +30 Ult. $=65$ Blk. +35 Wh.

XV. 89 Verm. + 11 Ult. $=89$ Blk. $+11 \mathrm{Wh}$.

Phil. Mag. S. 5. Vol. 34. No. 206. July 1892. I 
XVI. 94 Carm. +6 Ult. $=97$ Blk. +3 Wh.

XVII. 85 Br. gr. +15 Ult. $=90$ Blk. $+10 \mathrm{Wh}$.

XIX. 79 Verm. +21 Wh. $=62$ Em.gr. +17 Ult. +21 Bk.

XXI. 93 Carm. +7 Wh. $=84$ Br. gr. +9 Ult. +7 Bk.

Mr. Lloyd matched a Red of Chevreul's with No. 18 on the Yellow Gamme. To me it matched at the same time between Nos. 16 and 17.

For the indication of Dalton's vision see pages 102, 103.

The Two Brothers Carne.

I. 41 Y.+59 Ult. $=69$ Blk. +31 Wh.

IX. 42 Y. +39 Blk. +19 W. $=100$ Em. gr.

X. 7妾 Y. $+92 \frac{1}{4}$ Blk. $\quad=100$ Verm.

XIV. 62 Em. gr. +38 Ult. $=65$ Blk. $+35 \mathrm{Wh}$.

XV. 90 Verm. +10 Ult. $=95 \frac{1}{2}$ Blk. $+4 \frac{1}{2}$ Wh.

XIX. 75 Verm. +25 Wh. $=51 \frac{1}{2}$ Em.gr. +23 Ult. $+25 \frac{1}{2}$ Bk.

Messrs. Carne matched a Red of Chevreul's with No. 17 of the Yellow Gamme. To me it matched No. 16.

\section{Mr. PARRY.}

$$
\begin{aligned}
& \text { I. } 40 \text { Y. }+60 \text { Ult. } \\
& \text { II. } 54 \text { Y. }+46 \text { Ult. } \\
& \text { III. } 62 \mathrm{Y} .+38 \text { Ult. } \\
& \text { IV. } 43 \text { Y. }+57 \text { Ult. } \\
& \text { V. } 41 \text { Y. }+59 \text { Ult. } \\
& \text { VI. } 46 \text { Y. }+54 \text { Ult. } \\
& \text { VIII. } 35 \mathrm{Y} .+65 \mathrm{Wh} \text {. } \\
& \text { IX. } 43 \text { Y. }+44 \text { Blk. }+13 \text { Wh. }=100 \text { Em. gr. } \\
& \text { X. } 8 \text { Y. }+92 \text { Blk. } \quad=100 \text { Verm. } \\
& \text { XI. } 3 \text { Y. }+97 \text { Blk. }=100 \text { Carm. } \\
& \text { XII. } 15 \text { Y } .+83 \text { Blk. }+2 \text { Wh. }=100 \text { Br. gr. } \\
& \text { XIV. } 60 \text { Em. gr. }+40 \text { Ult. }=66 \text { Blk. }+33 \text { Wh. } \\
& \text { XV. } 90 \text { Verm. }+10 \text { Ult. }=92 \text { Blk. } 8 \text { Wh. }
\end{aligned}
$$

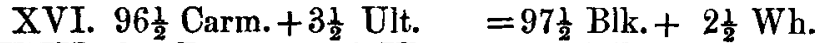

$$
\begin{aligned}
& \text { XVII. } 81 \frac{1}{2} \text { Br. gr. }+18 \frac{1}{2} \text { Ult. }=87^{2} \text { Blk. }+13 \text { Wh. } \\
& \text { XVIII. } 73 \text { Blue verd. }+27 \mathrm{Y} .=47 \frac{1}{2} \text { Blk. }+52 \frac{1}{2} \text { Wh. } \\
& \text { XIX. } 68 \text { Ver. }+23 \frac{1}{2} \text { Y. }+8 \frac{1}{2} \text { W. }=68 \text { Em. gr. }+32 \text { Blk. } \\
& \text { XX. } 87 \frac{1}{2} \text { Car. }+10 \frac{1}{2} \text { Y. }+2 \text { W. }=88 \text { Br. gr. }+12 \text { Blk. }
\end{aligned}
$$

Mr. Parry matched a Red of Chevreul's with No. 18 of the Yellow Gamme. To me it matched No. 16. He matched a Green of Chevreul's with No. 16 of the same Gamme. To me it matched No. 17. His perceptions of yellow and blue were exceedingly acute, even in the lightest tints. 

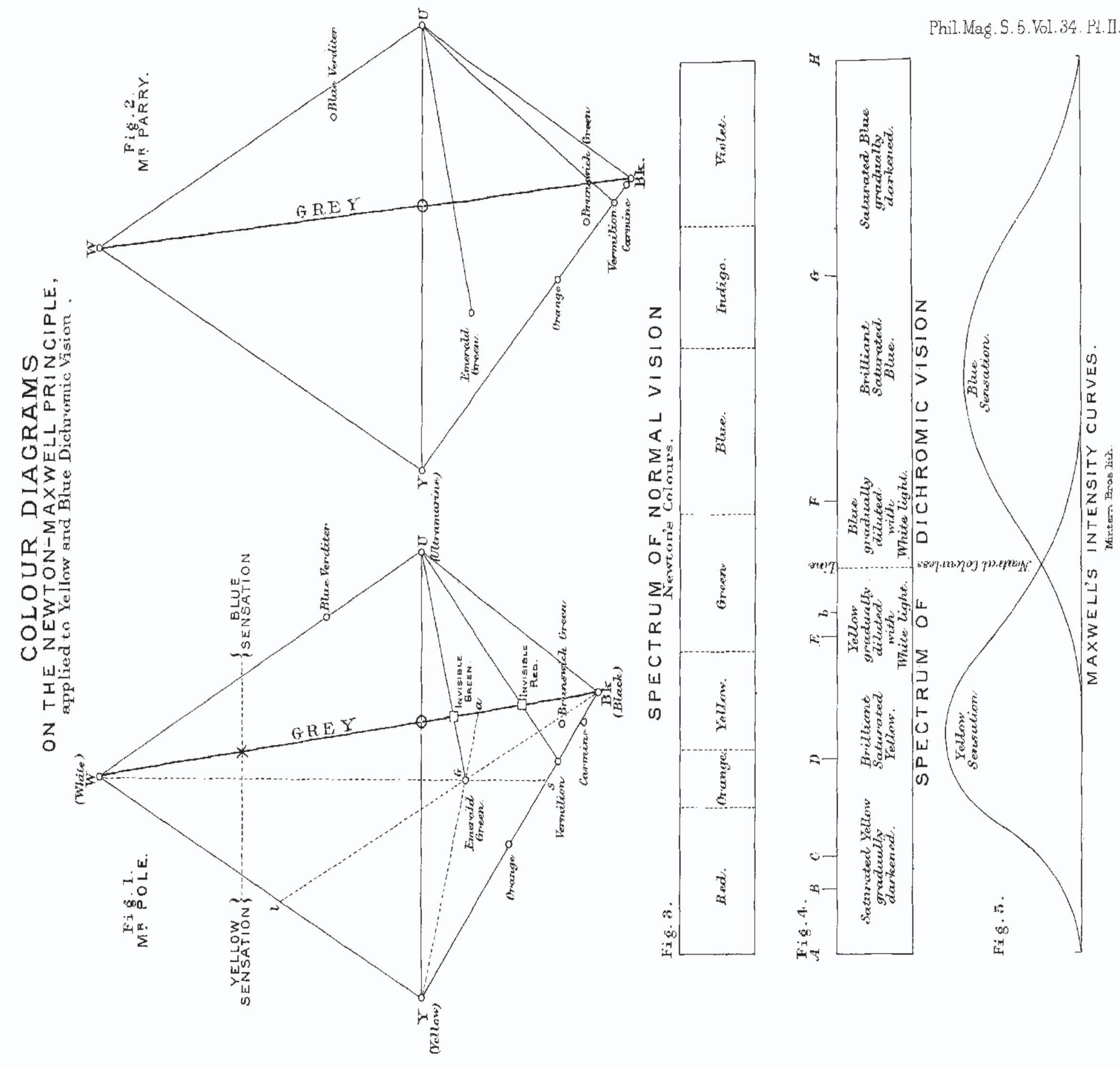